\title{
Effects of a tablet game intervention on simple addition and subtraction fluency in first graders
}

\author{
Frauke van der Ven*, Eliane Segers, Atsuko Takashima, Ludo Verhoeven \\ Behavioural Science Institute, Radboud University, P.O. Box 9104, 6500 HE Nijmegen, The Netherlands
}

\section{A R T I C L E I N F O}

\section{Article history:}

Received 20 November 2016

Received in revised form

3 February 2017

Accepted 9 February 2017

Available online 1 March 2017

\section{Keywords:}

Serious gaming

Mathematics

Arithmetic fluency

Computation

Automaticity

Elementary

\begin{abstract}
A B S T R A C T
In the present study, we aimed to playfully improve arithmetic fluency skills with a tablet game training. Participants were 103 grade 1 children from regular primary schools. The tablet game was tested with a pretest-posttest control group design, and consisted of a racing game environment in which the player competed against a virtual opponent by rapidly solving addition and subtraction problems up to 20 . During the 5-week intervention, one group $(n=52)$ practiced with the game while another group $(n=51)$ continued regular education without the game. Before, directly after, and three months after the intervention, we applied an arithmetic test to measure simple addition and subtraction skills in both symbolic (Arabic; 4) and non-symbolic (dots; ::) number notations. The intervention group increased significantly more on dot-subtraction efficiency than the control group, an effect which was prominent directly after the intervention. Since i) dot-subtraction is considered to rely more on calculation than the other arithmetic types that we measured and ii) the dot problem-answer representations were not practiced during the intervention, our results suggest that the tablet game promoted arithmetic fluency by benefitting calculation efficiency rather than retrieval efficiency or the switch from calculation to retrieval.
\end{abstract}

() 2017 Elsevier Ltd. All rights reserved.

\section{Introduction}

Fluency of basic arithmetic skills is important for advanced mathematical achievement (e.g., Geary, 2011; Patton, Cronin, Bassett, \& Koppel, 1997) and valuable in daily life. Towards the end of grade 1 , children are expected to become fluent in the addition and subtraction of simple sums. Such efficiency is gained through practice (e.g., Imbo \& Vandierendonck, 2008), but practice can become tedious (Hatfield, 1991). New technologies provide novel opportunities for engaging children (Flewitt, Messer, \& Kucirkova, 2014). An arithmetic tablet game may thus fit well into regular education. Yet, despite the call for evidence-based material, there is a lack of studies that assess the educational effectiveness of tablet games that are designed to increase arithmetic efficiency in grade 1 children. Therefore, this study examined the effects of a tablet game intervention on arithmetic efficiency in grade 1 . We assessed four types of arithmetic, namely Arabicaddition, Arabic-subtraction, dot-addition and dot-subtraction.

\footnotetext{
* Corresponding author.

E-mail address: f.vanderven@pwo.ru.nl (F. van der Ven).
}

Since these are thought to rely on different solution methods, namely 'calculation' and 'retrieval from factual memory', to a different degree, differential outcomes may provide clues as to where effects of a fluency intervention could be attributed.

\subsection{Arithmetic efficiency and solution methods}

The answer to a simple arithmetic problem can be calculated via (mental) manipulation of quantities. But once repeated practice has resulted in the memorization of a problem-answer association, the answer can be directly retrieved from factual memory without the need for calculation (Ashcraft, 1982; Dehaene, Piazza, Pinel, \& Cohen, 2003). Hence, arithmetic fluency can be promoted by i) a change from calculation to retrieval, because it is more efficient to retrieve an answer than to calculate it (Siegler, 1987), ii) an increase in calculation speed or iii) an increase in retrieval speed.

Whether one uses calculation or retrieval may be influenced by the arithmetic operation that is performed (addition, subtraction), and by the notation of numbers (non-symbolic, symbolic). In general, additions are learned before subtractions, and they may be practiced more regularly. As mentioned before, practice leads to stronger problem-answer representations (e.g., Ashcraft, 1982; 
Dehaene et al., 2003; Imbo \& Vandierendonck, 2008). Hence, simple additions have more stable memory representations, increasing the likelihood of retrieval as a preferred solution method. Indeed, several studies report a higher use of retrieval for additions than for subtractions (e.g., Campbell \& Xue, 2001; Henry \& Brown, 2008). The notation of numbers can also influence the way arithmetic problems are solved (Campbell \& Alberts, 2009; Campbell \& Fugelsang, 2001). Early arithmetic is performed on non-symbolic quantities, such as dots $(::+\cdot)$, and this direct presentation of quantity could encourage the use of quantity calculations (e.g., visually grouping) (cf. Rasmussen \& Bisanz, 2005). Before the start of primary school, children learn that non-symbolic quantities can be efficiently represented with symbols, such as Arabic numbers $(4,2)$, and this symbolic notation could be important for the memorization of problem-answer combinations and the direct retrieval of these arithmetic facts (Cantlon, 2012). Hence, a non-symbolic dot-notation is more likely to recruit calculation - and less likely to recruit retrieval from memory than a symbolic Arabic-notation. This effect of notation was recently supported by two imaging studies (children: Peters, Polspoel, Op de Beeck, \& De Smedt, 2016; adults: van der Ven, Takashima, Segers, Fernández, \& Verhoeven, 2016). In sum, an answer to a simple arithmetic problem can be calculated or retrieved from memory, and the solution method used depends on the arithmetic operation (more retrieval for addition than for subtraction) and the number notation (more retrieval for Arabic than for dots).

\subsection{Serious tablet games in the field of mathematics}

In order to train arithmetic fluency, whether it is by shifting the solution method from calculation to retrieval because of memorized problem-answer representations, or by becoming more efficient in calculation or retrieval itself, repetition is important (Imbo \& Vandierendonck, 2008). Unfortunately, repetition can become tedious (Hatfield, 1991) while student engagement is important for learning (Singh, Granville, \& Dika, 2002). In this regard, new technologies, such as tablet games, could be helpful.

Well designed digital games can be educationally valuable (Clark, Tanner-Smith, \& Killingsworth, 2015; Sitzmann, 2011; Vogel et al., 2006; Wouters, van Nimwegen, van Oostendorp, \& van der Spek, 2013). As an advantage to pen-and-paper practicing they provide the opportunity for direct feedback, such that students do not build on incorrect information (Kiili, 2005), but can strengthen intended relations, such as between an arithmetic problem and its accurate outcome (Ashcraft, 1982). Furthermore, digital games are reported to be more engaging than traditional education (e.g., Fabian, Topping, \& Barron, 2015; but, see also; Wouters et al., 2013). And, even though results are mixed (Kroesbergen \& Van Luit, 2003; Young et al., 2012), positive effects have been reported for interventions with maths games on (the more traditional) computers (e.g., Fuchs et al., 2006; Wilson, Revkin, Cohen, Cohen, \& Dehaene, 2006).

As an advantage to traditional computers, tablet computers are mobile which allows for anytime-anywhere learning. Also, their touch screens are easier to use and foster more intuitive interactions (Cooper, 2005). Moreover, young children consider tablets to be highly motivating (Flewitt et al., 2014), and in technologybased societies - where tablets gain popularity in both homes and schools - children are familiarized with these mobile computers when they are very young (Neumann \& Neumann, 2014). Hence, a tablet game could be an excellent candidate for engaging young children into practicing their arithmetic skills.

Many tablet games are available in the field of mathematics, but few have been tested on their effectiveness. A first meta-analysis, on studies using mobile devices for increasing mathematics in elementary school (Fabian et al., 2015), reveals overall positive achievement gains with a moderate effect size, and an increase in the number of studies that use tablets. However, thus far, intervention studies with mobile devices concentrated on numeracy skills in preschoolers (e.g., Schacter \& Jo, 2016; Schacter et al., 2016), or on higher order skills in the upper grades (e.g., Carr, 2012; Miller \& Robertson, 2010, 2011). Albeit arithmetic fluency is important, none of the current studies has focused on tablet gaming effects on simple-arithmetic fluency (addition + subtraction) in early graders.

A few investigations suggest that a well-designed tablet game could benefit the fluency of simple-arithmetic skills in early graders. Concerning arithmetic fluency, positive results were reported for playing with mobile digital games on general arithmetic efficiency in grade 4/5 (Main \& O'Rourke, 2011), and on multiplication efficiency in grade 3 (Kiger, Herro, \& Prunty, 2012). Concerning studies with a younger population, general maths gains have been reported by playing games on GameBoy-like devices (Rosas et al., 2003; Shin, Sutherland, Norris, \& Soloway, 2012), and a more recent study (Pitchford, 2015) suggested that tablet games can be incorporated into non-Western educational systems to enhance early mathematical skills. However, these latter studies did not specifically target simple-arithmetic fluency. Overall, tablet games may well be suited for encouraging children to repeatedly solve arithmetic problems, but there is a lack of tested tablet games that focus on promoting arithmetic fluency in early graders.

\subsection{The present study}

To promote arithmetic fluency in a playful and motivating setting, we developed a tablet game. In this game, children practiced addition and subtraction problems in Arabic numbers up to 20. The game was designed specifically to promote arithmetic efficiency - which is a combination of speed and accuracy and to engage the student. A player practiced arithmetic in a racing game environment by competing against a virtual opponent. The opponent's speed was adjusted to the player's own ability, such that the player raced against, and thereby improved, his or her own arithmetic efficiency. Accuracy was assured by providing the player with direct feedback and the opportunity to solve the problem again if an answer was incorrect. To encourage motivation, fun visuals and rewards were incorporated in challenging races attuned to the child's proficiency level. In addition, there was a variety of game types.

In the present study, we examined the effects of an intervention with this tablet game on arithmetic efficiency. The intervention was introduced to children at the end of grade 1 in the Dutch regular education system (6-7 years old). According to Dutch standards, these children are supposed to be able to correctly solve all additions and subtractions up to 20 , and they are at the stage of practicing to become fluent. One group played with the tablet game for 5 weeks at school, whereas another group continued regular education without the game. Before the intervention (pre) and directly after (post1), we tested their symbolic and non-symbolic addition and subtraction proficiency. These skills were retested at the beginning of grade 2 (post2) to examine longer-term effects.

We expected that playing with the tablet game would increase arithmetic efficiency. Since we used different operations (addition, subtraction) and notations (Arabic, dots) in the assessment, the pattern of results would indicate as to whether an increase in efficiency was mainly caused by i) a switch from calculation to retrieval, ii) accelerated calculation, or iii) accelerated retrieval. If the intervention promotes the memorization of sums and therefore a switch from calculation to retrieval (or accelerated retrieval), then the largest effects should be observed in the Arabic notations, because children practice Arabic addition and subtraction in the tablet game, and therefore these problem-answer associations are 
the most likely to be established and strengthened. If, playing with the tablet game mainly increases calculation speed, the greatest results should be observed for dot-subtraction, because the answers to these problems are most likely to be calculated. If alternatively, playing with the tablet game mainly improves retrieval speed, then benefits should primarily be observed for Arabicaddition, because these sums are the most likely to rely on verbal retrieval. Since children practiced Arabic-arithmetic fluency in the tablet game, we expected gains in arithmetic fluency, especially for Arabic arithmetic.

\section{Material and methods}

This study was part of a larger investigation. Below we only describe the information relevant for the present study.

\subsection{Participants}

In total, 103 children participated in the present study. The experimental group which received the tablet game intervention consisted of 52 children ( 25 females, $M(S D)$ age $=6.93(0.36)$ years), and the control group of 51 children (18 females, $M(S D)$ age $=7.22(0.39)$ years). Classes $(N=4)$ were pseudo-randomly assigned to either the experimental or control group, such that each group contained an equal number of children. All children were in grade 1 at the test points before (pre) and directly after the intervention (post1), and in grade 2 during the third measurement (post2). Parents gave informed consent, which was active or passive, depending on the school's regular practice.

\subsection{Procedure}

Fig. 1 shows the experimental design. First, all children received the pre-intervention measurements including the assessment of arithmetic skills. Next, the experimental group received the tablet game intervention, and the control group continued regular education. The intervention effects were tested at two time points, once immediately after the intervention period (post1) and again 13 weeks after the post1-test (post2).

Both children and teachers were instructed on how to use the tablet game. They were instructed to play the game for 15 min per session, four sessions a week, for five weeks within the allocated six weeks (one week was a vacation week), resulting in a total of 20 sessions. These gaming sessions were additional to rather than instead of the regular mathematics lessons.

\subsection{Materials}

\subsubsection{The tablet game}

2.3.1.1. Goals. The tablet application was designed to be a fun game to practice arithmetic skills (see Fig. 2 for screenshots). A child saw a particular arithmetic problem, and the goal was to correctly solve the problem as fast as possible. The game set-up was designed to encourage the child to improve his or her arithmetic skills in several ways.

First, arithmetic speed was promoted by the incorporation of a racing element. At the beginning of each race, two vehicles appeared on the left lower part of the screen, one in orange and another in grey. The child was the driver of the orange vehicle, and had to battle against the grey vehicle to get to the right upper corner first. Points could be collected along this trajectory. The faster the correct answer was given, the more virtual meters the orange vehicle gained in comparison to the grey vehicle. Unbeknownst to the child, the grey vehicle proceeded at the average speed of a child's prior arithmetic skills, as measured within a specific level. Therefore children were challenged to race against their own arithmetic speed.

Second, to ensure accuracy, a correct answer was positively reinforced, whereas an incorrect answer would result in gaining less meters relative to the competing vehicle. A child could select the correct answer on the screen with a finger, and swipe it onto the centre of the screen (answer area = the white box containing the problem). A correct answer was accompanied by stars shooting out and a positive sound. An incorrect answer resulted in a red cloud and a more negative sound. If the answer was incorrect, the child could try again until the correct answer was selected, but after each incorrect answer, the answer options were not selectable for $5 \mathrm{~s}$ which had a negative influence on the race.

Third, a child's motivation to play the game was promoted by several factors, such as the racing element, fun colours and visuals, a touch screen (swiping), and further by earning points and altitude meters to get to another scenery and vehicle. The overarching goal was to get to the highest altitude possible via several vehicles (from sea in a submarine, to land in a monster truck, to air in an air balloon, to outer world in a rocket, to outer space in a space ship). A certain amount of points was needed to receive a novel vehicle on a novel background in a higher altitude setting. After each racing game, a progress screen (see Fig. 2) showed the amount of points, and thus altitude gained, and gave the option for the child to stop or continue with the game. To keep the game fresh, for each child, the game started where the child had left off in the previous session (after the last finished racing game).

2.3.1.2. Stimuli and levels. The stimuli consisted of 231 addition and 231 subtraction problems up to 20 . All numbers were full integers, from 0 to 20 in Arabic notation. In total, there were 35 levels in the game, which were combinations of game type (see Fig. 2) and problem type.

Within each level, four to five racing games were played. Each racing game consisted of 12 problems which had to be answered correctly. The actual amount of racing games played within a level depended on an algorithm that calculated to what degree the increase in speed levelled off between racing games.

\subsubsection{Arithmetic skills}

Arithmetical skills were measured with an arithmetic test at three occasions. The test consisted of four pages with 54 problems each. A child had 1 min per page to solve as many problems as possible. Page 1 contained Arabic-addition, page 2 Arabic-subtraction, page 3 dot-addition, and page 4 dot-subtraction problems. The Arabic problems were sums up to 20 , with open answers (e.g., $[+8=7 ;[17-9=2)$. The dot problems were sums up to 9, with two answer options because of foreseen difficulties with writing of the answer (e.g., $+\cdot=:: ;$; $: r^{\circ}=\cdots$; the incorrect option was always one or two integers above or below the correct option, with the correct answer option equally distributed over the right and the left side). For Arabic-arithmetic, the efficiency scores represent the number of correctly answered problems within $1 \mathrm{~min}$. For dot-arithmetic (measured by a two alternative forced choice task), the efficiency scores were calculated as the number correct per minute minus the number incorrect per minute, thereby accounting for guessing.

There were three versions of the test. These contained identical problems, but in a different order. Each version was assigned to one of the three test-points, and the version/test-point combinations were counter-balanced across participants within a group. ${ }^{1}$ Because a child would not be able to finish all problems within a page, for

\footnotetext{
1 Two children received one version twice, but their test scores did not show outlying results.
} 


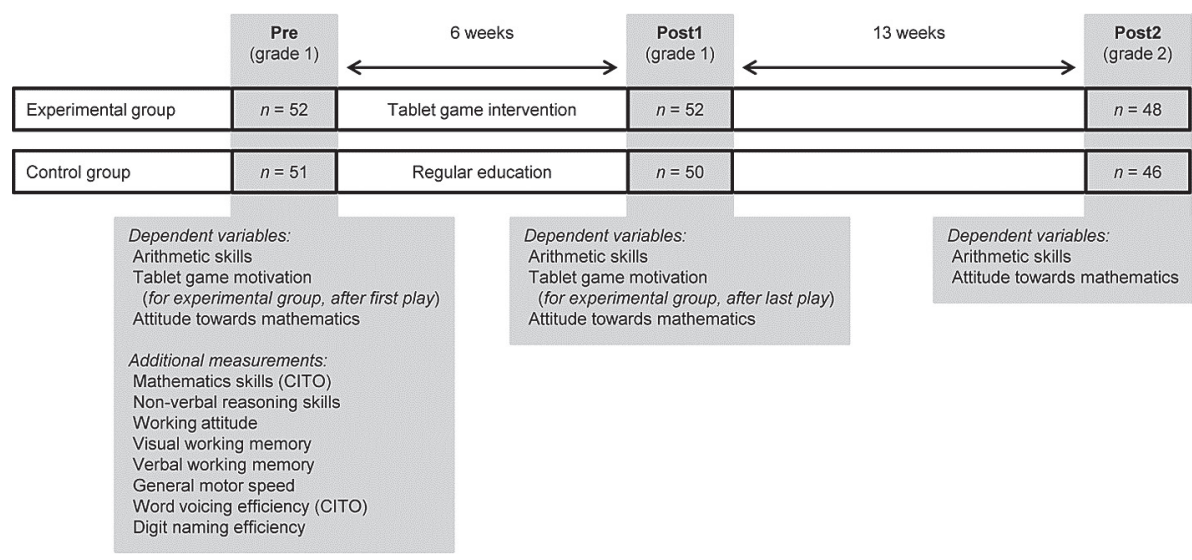

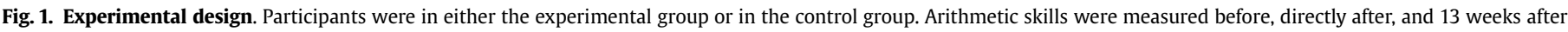
the intervention.

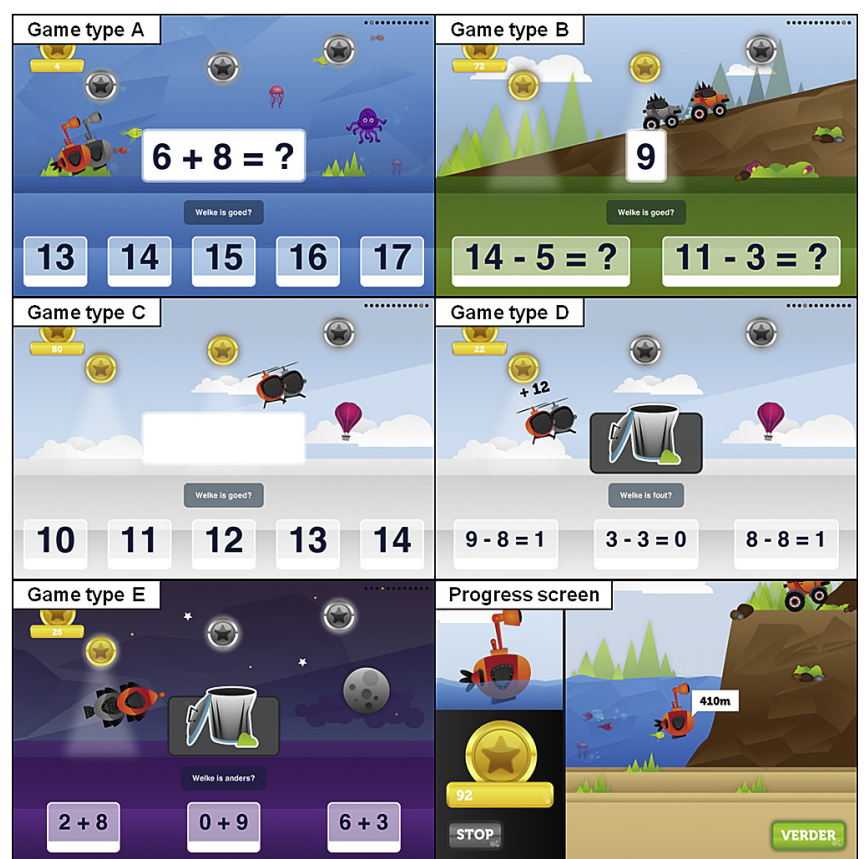

Fig. 2. Screenshots of the tablet game. A child had to select the correct answer (e.g. 14 in the upper left screenshot) and swipe it into the middle part of the screen. The faster the answer, the more altitude was gained as compared to the grey vehicle that the child raced against. The grey vehicle travelled at the mean speed based on the speed of previous racing games of the child within a particular level. Coins were collected along the way. The orange circle in the upper right indicated the progress within a racing game (e.g., the second out of 12 problems for the upper left screenshot). Note: 'Welke is goed?' is Dutch for 'Which one is correct?'. The levels consisted of a combination of game type and problem type. There were five game types: A) a problem appeared on the screen and the correct outcome had to be selected out of five options; B) an outcome appeared on the screen and the correct problem had to be selected out of two options; $\mathbf{C}$ ) same as $A$, but now the problem disappeared to promote mental calculation; D) three problems with answers appeared on the screen, and the incorrect combination had to be selected; E) three problems appeared on the screen, and the problem that had an outcome different from the other two had to be selected. There were seven problem types: 1 ) addition problems up to $10 ; 2$ ) subtraction problems from 10 downwards; 3) addition problems crossing 10 ; 4) subtraction problems crossing 10 ; 5) addition problems above 10 ; 6) subtraction problems above $10 ; 7)$ all addition and subtraction problems. After each racing game (12 correctly answered problems), the progress screen appeared. It showed the points/altitude gained, a peek at the next vehicle that the child would acquire when enough points/ meters would be gained, and the possibility to continue ('verder') or discontinue ('stop') with the game. each version the problems were pseudo-randomly divided over the pages to balance difficulty level over measurement points: For both Arabic-addition and Arabic-subtraction, problems up to 10, with 10 crossing, and above 10 , were equally distributed across the page. For dot-addition and subtraction (all $<10$ ), three difficulty levels were created on face value and equally distributed over the page. Furthermore, the addition problems were balanced on whether the first addend was larger or smaller than the second addend.

\subsubsection{Tablet game motivation}

To measure whether children enjoyed playing with the tablet application, after the first and the last session, they indicated how much they liked this arithmetic game (five point Likert item, accompanied with smileys and text: 1 (+sad smiley + 'no fun at all') = I don't like it at all; 5 (+happy smiley + 'very much fun') = I like it very much).

\subsubsection{Attitude towards mathematics}

To measure attitude towards mathematics class in school, children were asked how much they liked mathematics (five point Likert item, accompanied with smileys and text: 1 ( + sad smiley + 'no fun at all') $=$ I don't like it at all; 5 ( + happy smiley + 'very much fun') $=$ I like it very much) before each arithmetic test. This question was embedded within three foil questions (How much do you like school/reading/handicraft?).

\section{Results}

\subsection{Tablet game: statistics and motivation}

During the intervention, children played on average 14 sessions with the tablet game $(S D=2$, range $=6-17)$. At the end of the intervention, level 20 was reached on average $(S D=7$, range $=6-35)$ and 84 racing games were played $(S D=29$, range $=25-146)$, with a mean of $4.3(S D=0.2)$ racing games per finished level. After both their first and their last session, children rated the tablet game as very enjoyable (first session: $M=4.9$, $S D=0.2$; last session: $M=4.7, S D=0.7 ; \max =5.0$; means based on one school, because of missing 'after first play measurements' for the second school; 'after last play measurements' second school: $M=3.5, S D=1.5$ ). 
Table 1

Mean group descriptives (SD) and statistics.

\begin{tabular}{|c|c|c|c|c|c|c|c|c|}
\hline \multirow[b]{2}{*}{ Group } & \multirow[b]{2}{*}{$\begin{array}{l}\text { Mathematics skills } \\
\text { (CITO) })^{\mathrm{a}}\end{array}$} & \multirow[b]{2}{*}{$\begin{array}{l}\text { Non-verbal } \\
\text { reasoning skills }\end{array}$} & \multirow[b]{2}{*}{$\begin{array}{l}\text { Working } \\
\text { attitude }^{c}\end{array}$} & \multirow[b]{2}{*}{$\begin{array}{l}\text { Visual working } \\
\text { memory }^{\mathrm{d}}\end{array}$} & \multirow[b]{2}{*}{$\begin{array}{l}\text { Verbal working } \\
\text { memory }^{\mathrm{e}}\end{array}$} & \multirow[b]{2}{*}{$\begin{array}{l}\text { General motor } \\
\text { speed }^{\mathrm{f}}\end{array}$} & \multicolumn{2}{|c|}{ Technical reading skills } \\
\hline & & & & & & & $\begin{array}{l}\text { Word voicing } \\
\text { efficiency (CITO) }\end{array}$ & $\begin{array}{l}\text { Digit naming } \\
\text { efficiency }^{\mathrm{h}}\end{array}$ \\
\hline Experimental & 3.10 & 28.20 & 6.76 & 8.38 & 10.77 & 680 & 2.44 & 0.81 \\
\hline$(n=52)$ & $(1.38)$ & $(4.77)$ & $(6.31)$ & (3.99) & (3.37) & $(217)$ & $(1.35)$ & $(0.18)$ \\
\hline Control & 2.28 & 27.35 & 8.06 & 9.12 & 9.92 & 656 & 2.70 & 0.89 \\
\hline$\left(n=51^{\mathrm{i}}\right)$ & $(1.13)$ & $(4.65)$ & $(6.21)$ & $(4.39)$ & $(3.28)$ & $(165)$ & $(1.22)$ & $(0.27)$ \\
\hline$U$ & 852.00 & 1169.00 & 1481.00 & 1517.50 & 1165.00 & 1310.00 & 1471.50 & 1546.50 \\
\hline$P$ & .002 & .299 & .224 & .204 & .286 & .916 & .238 & .145 \\
\hline
\end{tabular}

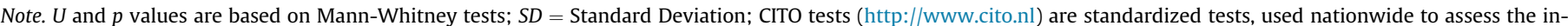
dividual progress of students in Dutch schools. For all, except the CITO scores and digit naming efficiency, a higher score reflects higher skills.

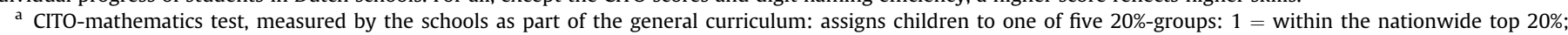

$5=$ within the nationwide lowest $20 \%$.

b Raven's Coloured Progressive Matrices (Van Bon, 1986): number correct.

c Eleven questions of the BRIEF (Huizinga \& Smidts, 2012): mean of quantified answers.

d Mr. X, a subtest of the Automated Working Memory Assessment (AWMA; Dutch version; Alloway, 2007): raw memory score.

e Listening recall, a subtest of the Automated Working Memory Assessment (AWMA; Dutch version; Alloway, 2007): raw memory score.

${ }^{f}$ Motor reaction time task (Brankaer, Ghesquière, \& De Smedt, 2014): mean speed (ms); percentage correct $=97 \%$.

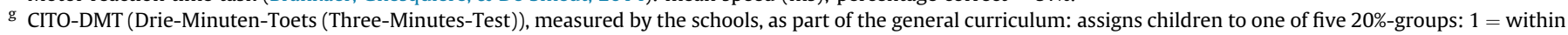
top $20 \%$, nationwide; 5 = within lowest $20 \%$, nationwide.

h Digit card of a rapid automatized naming task (van den Bos \& Lutje Spelberg, 2007): card reading speed (s) divided by number of correctly named digits.

${ }^{\mathrm{i}}$ For mathematics skills (CITO), working attitude, and word voicing efficiency (CITO), $n=50$.

\subsection{Before the intervention}

Prior to the intervention, the two groups (see Table 1 for the group descriptives and statistics) did not differ in terms of nonverbal reasoning skills, working attitude, visual and verbal working memory, general motor speed, and technical reading skills, suggesting that they came from the same population, although the experimental group performed less well on the curriculum bound mathematics test - a Dutch national test designed by the Centraal Instituut voor Toetsontwikkeling (CITO) than the control group. Nonetheless, independent t-tests showed that the experimental group and the control group scored similarly on our measures of interest, namely their arithmetic efficiency scores prior to the intervention (Arabic-addition: $p=.563$; Arabic-subtraction: $p=.581$; dot-addition: $p=.532$; dot-subtraction: $p=.132$ ) and their attitude towards mathematics $(p=.789)$.

\subsection{Intervention effects}

We miss data on 10 occasions: at post1, one child was ill, and at post2, nine children either repeated grade 1 or moved to another school. Therefore the following analyses are based on $n=48$ for the experimental group, and $n=45$ for the control group.

\subsubsection{Arithmetic skills}

The mean arithmetic test scores can be found in Table 2 (efficiency + accuracy) and Fig. 3 (efficiency). On average, 90.7 percent $(S D=6.0)$ of the arithmetic problems was answered correctly within a condition. This indicates that children understood the tasks at hand. Since accuracy was at ceiling level with many $100 \%$ scores, accuracy was not further investigated and we focused on efficiency.

To investigate the effect of the intervention on arithmetic efficiency, we performed two mixed analyses of variance (ANOVAs) one for Arabic-arithmetic, and one for dot-arithmetic with SumType (addition, subtraction) and Time (pre, post1, post2) as within-participant factors, and Group (experimental, control) as a between-participant factor. As the Arabic-arithmetic test was open-answer, and the dot-arithmetic test consisted of two alternative forced-choice questions, the two could not be compared in one analysis. Because the Arabic efficiency (residual) scores were not normally distributed (positive skew), for these we applied the square-root transformation before data analysis. Furthermore, we used the Greenhouse-Geisser correction if sphericity was violated.

For Arabic-arithmetic efficiency, there was neither a 3-way interaction ( $p=.525$ ), nor any 2 -way interactions (all $p \geq .153$; Group $\times$ Time: $p=.365)$, nor a main effect of Group $(p=.161)$. There was a main effect of Time $(F(1.85,168.57)=49.99, p<.001$, $\left.\eta_{\mathrm{p}}^{2}=.355\right)$, with a significant increase in efficiency from the pre-to post1-test ( $p<.001$ ), levelling off after the post1-test (post1 versus post2, $p=.193$ ). Also, a main effect of SumType was present $\left(F(1,91)=122.21, p<.001, \eta_{\mathrm{p}}^{2}=.573\right)$, with a higher efficiency for addition than for subtraction. Since no interaction effects between Group and Time were found, this suggests that the intervention did not have a beneficial effect on Arabic-arithmetic efficiency.

For dot-arithmetic efficiency, there was a Time $\times$ Group $\times$ SumType interaction $(F(2,174)=4.34, p=.014$, $\left.\eta_{\mathrm{p}}^{2}=.048\right)$. To interpret this interaction, we performed two separate mixed ANOVAs: one for dot-addition and one for dot-subtraction. For dot-addition, the Time $\times$ Group interaction was not significant $(p=.727)$, neither was the main effect of $\operatorname{Group}(p=.507)$, although there was a main effect of Time $(F(2,174)=41.85, p<.001$, $\left.\eta_{\mathrm{p}}^{2}=.325\right)$ revealing an efficiency increase from the pre-to post1test $(p<.001$; post 1 versus post $2, p=.052)$. For dot-subtraction, however, the Time $\times$ Group interaction was significant $\left(F(2,182)=8.08, p<.001, \eta_{\mathrm{p}}^{2}=.082\right)$. Two follow-up ANOVAs, the first excluding the post2-test, the second excluding the pre-test, showed that between pre and post1 the experimental group increased more in arithmetic efficiency than the control group $\left(F(1,91)=17.60, p<.001, \eta_{\mathrm{p}}^{2}=.162\right)$, whereas an efficiency difference between post 1 and post2 was similar for both groups $(p=.221)$. In spite of the latter, independent t-tests showed that only at the post1-test the experimental group scored significantly better on dot-subtraction efficiency than the control group (post1: $t(91)=2.25, p=.027$, Cohen's $d=.473$; post $2: p=.234$ ). Above results suggest that the tablet game intervention had a significant positive effect on dot-subtraction efficiency, that was prominent directly after the intervention.

3.3.1.1. Control analyses: mathematics skills (CITO). The general mathematics skills, measured by schools with the CITO-test as part 
Table 2

Mean efficiency scores (SD) and mean Accuracy scores (SD) on the arithmetic test.

\begin{tabular}{|c|c|c|c|c|c|c|c|}
\hline & Number notation & Arithmetic operation & Group & Pre & Post1 & Post2 & Difference score ${ }^{\mathrm{a}}$ : Post1-Pre \\
\hline \multirow[t]{8}{*}{ Efficiency $^{\mathrm{b}}$} & \multirow[t]{4}{*}{ Arabic } & \multirow[t]{2}{*}{ Addition } & Experimental & $8.6(4.8)$ & $11.8(5.5)$ & $11.8(4.8)$ & $3.3(3.5)$ \\
\hline & & & Control & $8.0(4.7)$ & $10.2(3.7)$ & $11.0(4.5)$ & $2.2(4.1)$ \\
\hline & & \multirow[t]{2}{*}{ Subtraction } & Experimental & $6.1(3.7)$ & $8.4(4.9)$ & $8.7(4.4)$ & $2.3(3.6)$ \\
\hline & & & Control & $5.8(3.6)$ & $7.1(3.7)$ & $7.3(4.5)$ & $1.3(3.3)$ \\
\hline & \multirow[t]{4}{*}{ Dots } & \multirow[t]{2}{*}{ Addition } & Experimental & $7.6(3.4)$ & $10.8(3.2)$ & $11.2(4.2)$ & $3.2(4.6)$ \\
\hline & & & Control & $7.0(4.2)$ & $9.6(4.5)$ & $11.0(3.5)$ & $2.9(3.7)$ \\
\hline & & \multirow[t]{2}{*}{ Subtraction } & Experimental & $6.1(3.6)$ & $8.1(4.6)$ & $8.4(3.8)$ & $2.0(4.1)$ \\
\hline & & & Control & $7.2(3.5)$ & $6.2(3.5)$ & $7.5(3.3)$ & $-1.0(2.8)$ \\
\hline \multirow[t]{8}{*}{ Accuracy $^{c}$} & \multirow[t]{4}{*}{ Arabic } & \multirow[t]{2}{*}{ Addition } & Experimental & $88.5(17.7)$ & $95.3(9.5)$ & $94.1(8.7)$ & $6.9(18.5)$ \\
\hline & & & Control & $87.5(18.2)$ & $89.5(14.9)$ & $92.3(11.1)$ & $2.0(21.1)$ \\
\hline & & \multirow[t]{2}{*}{ Subtraction } & Experimental & $78.5(21.0)$ & $83.2(15.3)$ & $85.6(14.4)$ & $4.6(21.0)$ \\
\hline & & & Control & $83.9(21.0)$ & $79.9(22.2)$ & $83.8(20.3)$ & $-4.1(22.8)$ \\
\hline & \multirow[t]{4}{*}{ Dots } & \multirow[t]{2}{*}{ Addition } & Experimental & $96.0(12.3)$ & $96.3(7.1)$ & $97.0(5.7)$ & $0.3(15.2)$ \\
\hline & & & Control & $94.8(16.8)$ & $93.5(13.6)$ & $96.4(6.0)$ & $0.4(13.7)$ \\
\hline & & \multirow[t]{2}{*}{ Subtraction } & Experimental & $94.8(13.0)$ & 94.7 (10.9) & 95.5 (9.7) & $-0.2(15.1)$ \\
\hline & & & Control & $94.5(13.0)$ & $88.3(17.2)$ & $92.1(12.1)$ & $-6.2(15.2)$ \\
\hline
\end{tabular}

Note. If a child had not made any sums in a certain category (4 occasions only), efficiency and accuracy were categorized as missing; $S D=$ Standard Deviation.

${ }^{a}$ Difference scores may not always match post1-pre because the difference was calculated for each participant before averaging.

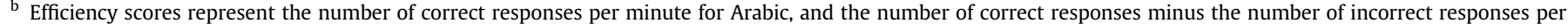
minute for dots.

c Accuracy scores represent the percentage correct (number of correct responses divided by the number of sums responded).
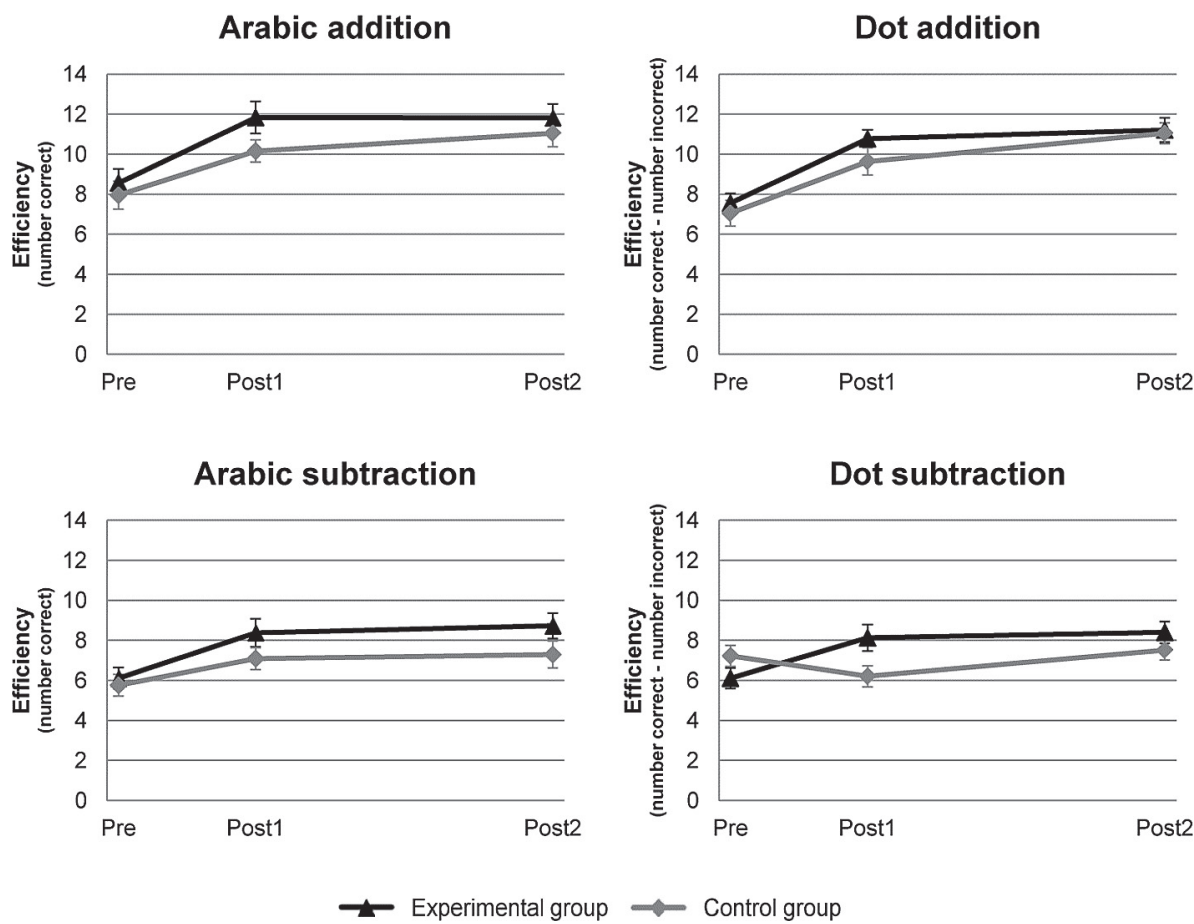

Fig. 3. Arithmetic efficiency scores $(M+S E)$, split on group and time.

of the Dutch curriculum, correlated with all our arithmetic-premeasurements (Arabic-addition: Spearman's $r=-.21 ; p=.048$; Arabic-subtraction: Spearman's $r=-.29 ; p=.004$; dot-addition: Spearman's $r=-.30 ; p=.005$; dot-subtraction: Spearman's $r=-$ $.460 ; p<.001$, all showing negative correlations, because lower CITO-scores reflect higher maths skills), which validates our arithmetic task. As the control group scored better on the CITOmathematics scores than the experimental group, we checked whether this would have had an effect on our results. The CITOscores did not correlate with the arithmetic increase from pre to post1 (all $p=.080$; within the experimental group only: all $p=.097)$. Moreover, including CITO-mathematics skill as a covariate in the previous analyses did not change the conclusions.

\subsubsection{Attitude towards mathematics}

A mixed ANOVA on mathematics attitude, with Group (experimental, control) as a between- and Time (pre, post1, post2) as a within-participant variable, revealed no significant effect of Time $(p=.100)$, Group $(p=.226)$, nor an interaction between Time and Group ( $p=.152$; $M$ pre $(S D), M$ post1 (SD), $M$ post2 (SD); experimental: 3.60 (1.51), 2.92 (1.61), 3.38 (1.59); control: 3.69 (1.53), 3.62 (1.60), 3.53 (1.62); $\max =5$ ).

\section{Discussion}

The goal of the present study was to investigate the effectiveness of a tablet game on increasing arithmetic fluency in an 
engaging manner. We found that the intervention was engaging and had a significant positive effect on dot-subtraction efficiency. The latter suggests that playing with the game benefitted the calculation operation, rather than retrieval speed or a switch from calculation to retrieval due to memorization.

It is likely that the intervention improved calculation efficiency because, i) dot subtraction is thought to be executed through calculation rather than retrieval, more so than the other measured arithmetic types, and ii) the dot problem-answer representations were not trained during the intervention. Contrary to our expectation, we did not find an effect on Arabic-arithmetic fluency. Possibly, the number of memorized Arabic problem-answer representations was already at ceiling level, or alternatively the intervention was too short to promote the memorization of these representations.

Our findings suggest that an arithmetic fluency tablet intervention can benefit calculation efficiency, probably by training mathematical insight. The tablet game focused on speeded responses, but also the relationships between quantities were trained (e.g., $9-5=8-4=4$ ). This knowledge about part-part-whole relations could have encouraged the use of transformation strategies (LeFevre, Sadesky, \& Bisanz, 1996) in which the child uses regrouping tricks for calculating the answer (e.g., 9-4 =8-4+1) as an efficient alternative to counting (e.g., Fischer, 1990; Hunting, 2003; Putnam, de Bettencourt \& Leinhardt, 1990; see also,; Baroody, Bajwa, \& Eiland, 2009). Adults mainly use a combination of calculation and retrieval (Campbell \& Fugelsang, 2001; Imbo \& Vandierendonck, 2008), which may be most advantageous for good mathematics: One cannot memorize all possible sums, and calculation methods are crucial when retrieval fails.

It is important to note that the effect of the intervention disappeared after the disuse of the tablet game. The influence of the game on arithmetic skills could be larger and more persistent if the intervention period is prolonged with additional playing sessions (cf. for a review: Clark et al., 2015).

On a practical level, a tablet game can be a fun method for improving calculation skills. In this regard, the current game can be used as a useful addition to, not a substitution for, grade 1 arithmetic-education. Caution is warranted, however, since with the current version of the game and the current time frame of the intervention, playing did not significantly benefit the Arabicarithmetic skills over and above regular education, and beneficial effects faded after disuse of the game. Although children's general attitude towards mathematics did not change, children enjoyed playing with the game. Therefore, one interesting venue is to exploit the possibility of anytime-anywhere learning and test the effects of long-term use of the tablet game at home. Also one has to consider that results may differ per age-group. Possibly, effects are larger, and significant for all arithmetic efficiency outcomes when tested in children that have started learning arithmetic only recently, such as preschoolers or children at the start of grade 1 . These children are even more likely to truly manipulate quantities in order to solve sums and may therefore benefit more from understanding the relationships between sums. Conversely, in older children, if quantity relations are well understood, the tablet game may promote memorization or retrieval speed rather than accelerating calculation processes.

Two limitations of this study are that individuals were not randomly assigned to the experimental or control group, and that the control group followed regular education only. Even though our pre-measurements did not suggest differences between the two groups, the former limitation might have resulted in unknown confounds that enhanced or decreased the effects of the tablet game intervention. Because of the latter limitation it is possible that the greater increase in arithmetic efficiency in the experimental group was achieved by extra training rather than by practice in an engaging environment per se. The present tablet application could be improved in iterations, by consulting teachers and learning from novel studies. Nonetheless, this study provides promising evidence for the educational value of tablet-based arithmetic fluency training in first graders.

In conclusion, playing with the arithmetic fluency tablet game in grade 1 was engaging and appeared to benefit arithmetic fluency by improving the calculation process, rather than by speeding up retrieval or increasing the number of memorized answers causing a calculation-to-retrieval switch. Accordingly, we have shown that a tablet-based arithmetic-fluency-training could help children in becoming more efficient in calculation processes in the early stage of arithmetic education. Future studies should make clear whether similar games may also help children to enhance memorization and retrieval fluency in more advanced stages of arithmetic development.

\section{Acknowledgements}

This work was supported by the National Initiative Brain and Cognition (NIHC; 056-35-013, https://www.hersenenencognitie. $\mathrm{nl})$. The tablet game was designed by the authors of this article in cooperation with QLVR software designers (http://qlvr.co). We thank Eelke Payens, Mirthe van der Made and Susan Wissink for helping with the data collection.

\section{References}

Alloway, T. P. (2007). Automated working memory assessment (AWMA). London: Pearson Assessment.

Ashcraft, M. H. (1982). The development of mental arithmetic: A chronometric approach. Developmental Review, 2(3), 213-236. http://dx.doi.org/10.1016/ 0273-2297(82)90012-0.

Baroody, A. J., Bajwa, N. P., \& Eiland, M. (2009). Why can't Johnny remember the basic facts? Developmental Disabilities Research Reviews, 15(1), 69-79. http:// dx.doi.org/10.1002/ddrr.45.

van den Bos, K. P., \& Lutje Spelberg, H. C. (2007). Continu Benoemen and Woorden Lezen. Een test voor het diagnosticeren van taal- en leesstoornissen. [Continuous Naming and Word Reading. A test for diagnosing language and reading disorders.] Amsterdam, the Netherlands: Boom Testuitgevers.

Brankaer, C., Ghesquière, P., \& De Smedt, B. (2014). Children's mapping between non-symbolic and symbolic numerical magnitudes and its association with timed and untimed tests of mathematics achievement. PloS One, 9(4), e93565. http://dx.doi.org/10.1371/journal.pone.0093565.

Campbell, J. I. D., \& Alberts, N. (2009). Operation-specific effects of numerical surface form on arithmetic strategy. Journal of Experimental Psychology: Learning, Memory, and Cognition, 35(4), 999-1011. http://dx.doi.org/10.1037/a0015829.

Campbell, J. I. D., \& Fugelsang, J. (2001). Strategy choice for arithmetic verification: Effects of numerical surface form. Cognition, 80(3), B21-B30. http://dx.doi.org/ 10.1016/S0010-0277(01)00115-9.

Campbell, J. I. D., \& Xue, Q. (2001). Cognitive arithmetic across cultures. Journal of Experimental Psychology: General, 130(2), 299-315. http://dx.doi.org/10.1037/ 0096-3445.130.2.299.

Cantlon, J. F. (2012). Math, monkeys, and the developing brain. Proceedings of the National Academy of Sciences, 109(Supplement 1), 10725-10732. http:// dx.doi.org/10.1073/pnas.1201893109.

Carr, J. M. (2012). Does math achievement h'APP'en when iPads and game-based learning are incorporated into fifth-grade mathematics instruction? Journal of Information Technology Education: Research, 11(1), 269-286.

Clark, D. B., Tanner-Smith, E. E., \& Killingsworth, S. S. (2015). Digital games, design, and learning: A systematic review and meta-analysis. Review of Educational Research, 1-44. http://dx.doi.org/10.3102/0034654315582065. online publication.

Cooper, L. Z. (2005). Developmentally appropriate digital environments for young children. Library Trends, 54(2), 286-302. http://dx.doi.org/10.1353/ lib.2006.0014.

Dehaene, S., Piazza, M., Pinel, P., \& Cohen, L. (2003). Three parietal circuits for number processing. Cognitive Neuropsychology, 20(3-6), 487-506. http:// dx.doi.org/10.1080/02643290244000239.

Fabian, K., Topping, K. J., \& Barron, I. G. (2015). Mobile technology and mathematics: Effects on students' attitudes, engagement, and achievement. Journal of Computers in Education, 1-28. http://dx.doi.org/10.1007/s40692-015-0048-8. online publication.

Fischer, F. E. (1990). A part-part-whole curriculum for teaching number in the kindergarten. Journal for Research in Mathematics Education, 21(3), 207-215. 
http://dx.doi.org/10.2307/749374

Flewitt, R., Messer, D., \& Kucirkova, N. (2014). New directions for early literacy in a digital age: The iPad. Journal of Early Childhood Literacy, 1-22. http://dx.doi.org $10.1177 / 1468798414533560$.

Fuchs, L. S., Fuchs, D., Hamlet, C. L., Powell, S. R., Capizzi, A. M., \& Seethaler, P. M. (2006). The effects of computer-assisted instruction on number combination skill in at-risk first graders. Journal of Learning Disabilities, 39(5), 467-475. http://dx.doi.org/10.1177/00222194060390050701.

Geary, D. C. (2011). Cognitive predictors of achievement growth in mathematics: A 5-year longitudinal study. Developmental Psychology, 47(6), 1539-1552. http:// dx.doi.org/10.1037/a0025510.

Hatfield, M. M. (1991). The effect of problem-solving software on student's beliefs about mathematics: A qualitative study. Computers in the Schools, 8(4), 21-40. http://dx.doi.org/10.1300/J025v08n04_04.

Henry, V. J., \& Brown, R. S. (2008). First-grade basic facts: An investigation into teaching and learning of an accelerated, high-demand memorization standard. Journal for Research in Mathematics Education, 39(2), 153-183. http://dx.doi.org $10.2307 / 30034895$.

Huizinga, M., \& Smidts, D. P. (2012). BRIEF Vragenlijst executieve functies voor 5-tot 18-jarigen. Amsterdam: Hogrefe Uitgevers.

Hunting, R. P. (2003). Part-whole number knowledge in preschool children. The Journal of Mathematical Behavior, 22(3), 217-235. http://dx.doi.org/10.1016/ S0732-3123(03)00021-X.

Imbo, I., \& Vandierendonck, A. (2008). Practice effects on strategy selection and strategy efficiency in simple mental arithmetic. Psychological Research, 72(5), 528-541. http://dx.doi.org/10.1007/s00426-007-0128-0.

Kiger, D., Herro, D., \& Prunty, D. (2012). Examining the influence of a mobile learning intervention on third grade math achievement. Journal of Research on Technology in Education, 45(1), 61-82. http://dx.doi.org/10.1080/ 15391523.2012 .10782597$.

Kiili, K. (2005). Digital game-based learning: Towards an experiential gaming model. The Internet and Higher Education, 8(1), 13-24. http://dx.doi.org/10.1016 j.iheduc.2004.12.001.

Kroesbergen, E. H., \& Van Luit, J. E. H. (2003). Mathematics interventions for children with special educational needs: A meta-analysis. Remedial and Specia Education, 24(2), 97-114. http://dx.doi.org/10.1177/07419325030240020501.

LeFevre, J.-A., Sadesky, G. S., \& Bisanz, J. (1996). Selection of procedures in menta addition: Reassessing the problem size effect in adults. Journal of Experimental Psychology: Learning, Memory, and Cognition, 22(1), 216-230. http://dx.doi.org/ 10.1037/0278-7393.22.1.216.

Main, S. \& O'Rourke, J. (2011). 'New directions for traditional lessons': Can handheld game consoles enhance mental mathematics skills? Australian Journal of Teacher Education, 36(2), 43-55. http://dx.doi.org/10.14221/ajte.2011v36n2.4.

Miller, D. J., \& Robertson, D. P. (2010). Using a games console in the primary classroom: Effects of 'Brain Training'programme on computation and selfesteem. British Journal of Educational Technology, 41(2), 242-255. http:// dx.doi.org/10.1111/j.1467-8535.2008.00918.x.

Miller, D. J., \& Robertson, D. P. (2011). Educational benefits of using game consoles in a primary classroom: A randomised controlled trial. British Journal of Educational Technology, 42(5), 850-864. http://dx.doi.org/10.1111/j.1467 $8535.2010 .01114 \mathrm{x}$

Neumann, M. M., \& Neumann, D. L. (2014). Touch screen tablets and emergent literacy. Early Childhood Education Journal, 42(4), 231-239. http://dx.doi.org/ 10.1007/s10643-013-0608-3.

Patton, J. R., Cronin, M. E., Bassett, D. S., \& Koppel, A. E. (1997). A life skills approach to mathematics instruction: Preparing students with learning disabilities for the real-life math demands of adulthood. Journal of Learning Disabilities, 30(2), 178-187. http://dx.doi.org/10.1177/002221949703000205.

Peters, L., Polspoel, B., Op de Beeck, H., \& De Smedt, B. (2016). Brain activity during arithmetic in symbolic and non-symbolic formats in 9-12 year old children.
Neuropsychologia, $\quad 86$ j.neuropsychologia.2016.04.001.

$19-28$.

http://dx.doi.org/10.1016/

Pitchford, N. J. (2015). Development of early mathematical skills with a tablet intervention: A randomized control trial in Malawi. Frontiers in psychology, 6(485), 1-12. http://dx.doi.org/10.3389/fpsyg.2015.00485.

Putnam, R. T., de Bettencourt, L. U., \& Leinhardt, G. (1990). Understanding of derived-fact strategies in addition and subtraction. Cognition and Instruction, 7(3), 245-285. http://dx.doi.org/10.1207/s1532690xci0703_3.

Rasmussen, C., \& Bisanz, J. (2005). Representation and working memory in early arithmetic. Journal of Experimental Child Psychology, 91(2), 137-157. http:// dx.doi.org/10.1016/j.jecp.2005.01.004.

Rosas, R., Nussbaum, M., Cumsille, P., Marianov, V., Correa, M., Flores, P., et al. (2003). Beyond nintendo: Design and assessment of educational video games for first and second grade students. Computers \& Education, 40(1), 71-94. http://dx.doi.org/10.1016/S0360-1315(02)00099-4.

Schacter, J., \& Jo, B. (2016). Improving low-income preschoolers mathematics achievement with Math Shelf, a preschool tablet computer curriculum. Computers in Human Behavior, 55(Part A), 223-229. http://dx.doi.org/10.1016/ j.chb.2015.09.013.

Schacter, J., Shih, J., Allen, C. M., DeVaul, L., Adkins, A. B., Ito, T., et al. (2016). Math shelf: A randomized trial of a prekindergarten tablet number sense curriculum. Early Education and Development, 27(1), 74-88. http://dx.doi.org/10.1080/ 10409289.2015.1057462.

Shin, N., Sutherland, L. M., Norris, C. A., \& Soloway, E. (2012). Effects of game technology on elementary student learning in mathematics. British Journal of Educational Technology, 43(4), 540-560. http://dx.doi.org/10.1111/j.14678535.2011.01197.x.

Siegler, R. S. (1987). The perils of averaging data over strategies: An example from children's addition. Journal of Experimental Psychology: General, 116(3), 250-264. http://dx.doi.org/10.1037/0096-3445.116.3.250.

Singh, K., Granville, M., \& Dika, S. (2002). Mathematics and science achievement: Effects of motivation, interest, and academic engagement. The Journal of Educational Research, 95(6), 323-332. http://dx.doi.org/10.1080/ 00220670209596607.

Sitzmann, T. (2011). A meta-analytic examination of the instructional effectiveness of computer-based simulation games. Personnel Psychology, 64(2), 489-528. http://dx.doi.org/10.1111/j.1744-6570.2011.01190.x.

Van Bon, W. H. J. (1986). Raven's coloured progressive matrices: Nederlandse normen en enige andere uitkomsten van onderzoek. Swets \& Zeitlinger.

van der Ven, F., Takashima, A., Segers, E., Fernández, G., \& Verhoeven, L. (2016). Nonsymbolic and symbolic notations in simple arithmetic differentially involve intraparietal sulcus and angular gyrus activity. Brain Research, 1643, 91-102. http://dx.doi.org/10.1016/j.brainres.2016.04.050.

Vogel, J. J., Vogel, D. S., Cannon-Bowers, J., Bowers, C. A., Muse, K., \& Wright, M (2006). Computer gaming and interactive simulations for learning: A metaanalysis. Journal of Educational Computing Research, 34(3), 229-243. http:// dx.doi.org/10.2190/FLHV-K4WA-WPVQ-HOYM.

Wilson, A. J., Revkin, S. K., Cohen, D., Cohen, L., \& Dehaene, S. (2006). An open trial assessment of "The Number Race", an adaptive computer game for remediation of dyscalculia. Behav Brain Funct, 2, 20. http://dx.doi.org/10.1186/1744-9081-220.

Wouters, P., van Nimwegen, C., van Oostendorp, H., \& van der Spek, E. D. (2013). A meta-analysis of the cognitive and motivational effects of serious games. Journal of Educational Psychology, 105(2), 249-265. http://dx.doi.org/10.1037| a0031311.

Young, M. F., Slota, S., Cutter, A. B., Jalette, G., Mullin, G., Lai, B., et al. (2012). Our princess is in another castle: A review of trends in serious gaming for education. Review of Educational Research, 82(1), 61-89. http://dx.doi.org/10.3102/ 0034654312436980. 